\title{
Is Psychiatric Nursing Effacing in Nigeria?
}

\author{
Panmial Priscilla Damulak* \\ Department of Public Health, Faculty of Basic Medical Sciences, Baze University, Nigeria \\ *Corresponding author: Panmial Priscilla Damulak, Department of Public Health, Faculty of Basic Medical Sciences, Baze \\ University, Abuja, Nigeria
}

\section{ARTICLE INFO}

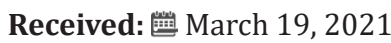

Published: 幽 April 16, 2021

Citation: Panmial Priscilla Damulak. Is Psychiatric Nursing Effacing in Nigeria? Biomed J Sci \& Tech Res 35(1)-2021. BJSTR. MS.ID.005657.

\begin{abstract}
The rising trend in mental illness in Nigeria has led to serious concerns for healthcare providers. Even more worrisome, is the misconceptions surrounding this illness and the healthcare providers particularly nurses managing the condition. Psychiatric nurses are faced with several challenges ranging from shortage of staff to stigma from the society. Other challenges affecting psychiatric nursing is the rebuttal by nursing students to advance their careers in psychiatric nursing. These issues could be curbed if misconceptions surrounding mental illness are corrected in the society, which may in turn influence career choices of nursing students towards psychiatric nursing.
\end{abstract}

\section{Challenges of Mental Health}

Mental ill health continues to remain a misunderstood phenomenon associated with widespread misconception and prejudice. Negative attitudes and beliefs surrounding mental illness abound which stimulate the general fear, rejection and discrimination against victims. This poses great concern because the global burden of mental health disorders is projected to reach $15 \%$ by the year 2020 . As such, common mental disorders such as depression, anxiety, and substance abuse-related disorders are predicted to incapacitate more people than complications arising from AIDS, heart disease, accidents, and wars combined [1]. If this disturbing statistic is the case, then it is as a matter of urgency, crucial to give mental health illness the close attention it requires. In Nigeria, a significant proportion (20\% to $30 \%$ ) of the population are believed to be affected by one or more mental disorders [2] unfortunately, regardless of the pint-size responsiveness accorded mental health, there is poor awareness and understanding of mental health in the country. This is reflected in the unfavorable attitude directed at mentally ill patients in Nigeria, probably influenced by preconceived ideas held against mental illness.

In Nigeria, a significant number of people suffer from mental illness and unfortunately, mental health happens to be the most neglected aspect of health in the country. Mentally ill patients are faced with numerous challenges such as poor mental health services, poor financing of mental health programs, limited access to available services and also limited number of providers [2]. Even more worrisome is the misconceptions held against people suffering from mental health challenges in the society. Often times, the society interacts with people with mental disorders from a prejudiced perspective, mostly stemming from stigma. According to Onyemelukwe [2], stigma continually remains the most rudimentary, cultural and moral impediment to the relief of mental health challenges thereby abusing human rights and impacting negatively on the dignity of mentally disabled persons as human beings.

One of the major challenges in the management of mental illness in Nigeria is the shortage in number of health care facilities and mental health care professionals or the inadequacy of wellequipped facilities to handle the burden of mental illness [3]. Another issue is the societal preference to safeguard care rendered to physical health problems rather than mental illness [4]. This occurs because of thriving misconceptions and stigma common with marginal groups, of which mental illness is not an exception and continues to remain a misunderstood phenomenon [5]. In addition, several barriers to access and acceptance of mental illness treatment in Nigeria persist such as poor understanding of the aetiology of mental illness, poor facility funding, absence of social support (family, friends, neighbors), fear of stigmatization regarding being labelled as mentally ill or being in association 
with the mentally ill, and patronage to traditional native healers who may unsuspectingly extend the illness, instead of tackling and treating them due to illiteracy and nonstandard treatments [3].

\section{Challenges of Psychiatric Nursing}

The dearth of specialists or experts in the field of psychiatry is another disturbing challenge [6]. Particularly, psychiatric nurses are scarce compared to the number of nurses in other specialties [7]. In 2014, it was reported that there were only about 7.7 nurses per 100,000 people and one psychiatrist for the same population in nearly half of the world's population [8]. This evident shortage has gross implications on the field of psychiatric nursing and even psychiatry as a whole. Past studies have also reported the repudiation of nursing and medical students to further their careers in psychiatry. The study by Samari, et al. [9] reported that $78.2 \%$ of nursing and medical students were not interested in specializing in psychiatry and also had unfavorable attitude towards psychiatry. Other studies have reported prevailing negative attitudes towards mental illness among medical and nursing students [10-12]. Similarly, some studies have also revealed negative attitude towards mental illness among health professionals [13-14] although some studies reported positive attitudes [15-16].

\section{Factors Influencing Psychiatry as a Career Choice}

While there are numerous factors influencing the choice of specialty for an individual, the perception an individual or the society holds regarding that field of specialization is essential. There are several factors responsible for the unfavorable attitude towards psychiatry by health care workers and their students; they include job opportunities, credibility and influence, income, and advanced educational prospects [17]. Of major concern is the low treatment success stories associated with psychiatry, this is because a good number of psychiatric patients fail to recover fully or relapse often. These and many more contribute immensely to the pessimistic view of psychiatry held by the public and health care professionals [9]. Additionally, societal preconceived ideas and misperceptions that exist about psychiatric patients and psychiatric settings contribute greatly to the negative opinions and attitudes held towards them. Often, these patients are considered to be unpredictable, dangerous and unlikeable and such stigmatization occurs globally [9]. The most unfortunate part of this stigmatizing stereotypes is that it extends to the health care professionals attending to them (stigma by association) for instance, psychiatric nurses have been described as less skilled, not dynamic and accorded less respect compared to their peers in other fields [18]. This often leads to lower job satisfaction and emotional exhaustion thus making psychiatry less appealing [19].

Furthermore, Heyman [5] stressed that health professionals who worked with mental health services have always been the subject of misconceptions in the public sphere and among their peers. The concept of "courtesy stigma" which is stigma by association has been used to explain these effects. Courtesy stigma, as argued by $\mathrm{Ng}$, et al. [20] is a reality dwelling amongst psychiatric nurses not because they relate to the disease but by their connection with the way the society views mental illness in its entirety. They added that research have reported obnoxious views of the public about psychiatric nurses as evil, mentally abnormal corrupt. The skills and roles of psychiatric nurses are underappreciated. In their study, Ng et al. (2010) reported that misconceptions on psychiatric nursing held by other nurses include:

a) Poor patronage as a specialty compared to other specialties.

b) Uncomplicated knowledge and skill base.

c) Poor vision for prospective development.

d) It should be considered an after-thought career: probably a second specialty.

In a bid to address the existing and uprising stigma and misconceptions about psychiatric nursing, the Nursing and Midwifery council (NMC) in 2010 stated that health practitioners must endeavor to endorse mental health and wellbeing in their interaction with patients, as well as defy the disparities and discrimination stemming or contributing to mental health issues. Also, they stated the importance of fostering mental health awareness by offering advice and encouragement to all health care professionals irrespective of their disciplines, in social care and health settings [5].

\section{Conclusion}

In conclusion, a paradigm shift is required in psychiatric nursing urgently, and this can only be achieved through collective effort of psychiatric nurses and nurses in other fields. Misconceptions regarding mental illness and psychiatric nursing should be dispelled first, this could be achieved through the following recommendations:

a) Nurse training schools should strengthen the psychiatric training component in their curriculum with psychiatric clinical postings so as to instill and encourage favorable attitudes toward mental illness and psychiatry.

b) Remuneration package of psychiatric nurses should be made more attractive by including certain allowances in order to boost patronage in psychiatric nursing specialty.

c) Government and policy makers could liaise with psychiatric schools and departments to design awareness and sensitization seminars and workshops in communities on mental health and illness to aid in waning off misconceptions.

d) Further studies relating to misconceptions on mental illness and psychiatric nursing should be conducted especially among nurses and nursing students. 


\section{Conflict of Interests}

None.

\section{References}

1. Ngui EM, Khasakhala L, Ndetei D, Roberts LW (2010) Mental disorders health inequalities and ethics: A global perspective. International Review of Psychiatry 22(3): 235-244.

2. Onyemelukwe C (2016) Stigma and mental health in Nigeria: Some suggestions for law reform. J Law Policy Glob 55: 63-68.

3. Urigwe SE (2010) Understanding mental illness in Nigeria: Bringing culture and traditional medicine into mental health policy.

4. Sharac J, Mccrone P, Clement S, Thornicroft G (2010) The economic impact of mental health stigma and discrimination: a systematic review. Epidemiology and Psychiatric Sciences 19(3): 223-232.

5. Heyman I (2012) Challenging misconceptions about mental health nursing. Nursing Times [online] 108: 16-17.

6. Katschnig H (2010) Are psychiatrists an endangered species? Observations on internal and external challenges to the profession. World Psychiatry 9(1): 21-28.

7. Browne G, Cashin A, Graham I, Shaw W (2013) Addressing the mental health nurse shortage: Undergraduate nursing students working as assistants in nursing in inpatient mental health settings. International Journal of Nursing Practice 19(5): 539-545.

8. (2017) World Health Organization.

9. Samari E, Seow E, Chua BY, Ong HL, Lau YW, et al. (2019) Attitudes towards psychiatry amongst medical and nursing students in Singapore. BMC medical education 19(1): 91.

10. Poreddi V, Thimmaiah R, Bada Math S (2017) Medical and nursing students' attitudes toward mental illness: An Indian perspective. Investigacion y educacion en enfermeria 35(1): 86-94.

ISSN: 2574-1241

DOI: 10.26717/BJSTR.2021.35.005657

Panmial Priscilla Damulak. Biomed J Sci \& Tech Res

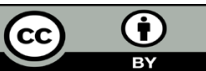

This work is licensed under Creative Commons Attribution 4.0 License

Submission Link: https://biomedres.us/submit-manuscript.php
11. Sreeraj VS, Parija S, Uvais NA, Mohanty S, Kumar S (2017) Indian nursing students' attitudes toward mental illness and persons with mental illness. Industrial psychiatry journal 26(2): 223-227.

12. El magd Luma MHA, Zamil A, Jordan UA (2013) Medical and Non-Medical Female Students' Attitudes toward Mental Illness and Psychiatric Patientsat Umm Al Qura University. Life Science Journal 10(2): 882-888.

13. Solanki CK, Shah HM, Vankar GK, Parikh MN (2017) Attitude toward mental illnesses among paramedical professionals and junior doctors. Annals of Indian Psychiatry 1(2): 102-108.

14. Mukesh K, Palayat AM, Yesudas KF, Divakaran B (2017) Attitude towards mental illness among staff nurses in a tertiary care hospital-a hospitalbased cross-sectional study. Journal of Evolution of Medical and Dental Sciences 6(27): 2231-2235.

15. Alshowkan A (2015) Nurse's attitude toward people with mental illness. European Psychiatry 30(S1): 28-31.

16. Gurung G (2014) Knowledge and attitude of nurses regarding mental illness. Journal of Chitwan Medical College 4(2): 40-43

17. Kuhnigk O, Hofmann M, Böthern AM, Haufs C, Bullinger M, et al. (2009) Influence of educational programs on attitudes of medical students towards psychiatry: Effects of psychiatric experience, gender, and personality dimensions. Medical teacher 31(7): e303-e310.

18. Henderson C, Noblett J, Parke H, Clement S, Caffrey A, et al. (2014) Mental health-related stigma in health care and mental health-care settings. The Lancet Psychiatry 1(6): 467-482.

19. Verhaeghe M, Bracke P (2012) Associative stigma among mental health professionals: implications for professional and service user well-being. Journal of health and social behavior 53(1): 17-32.

20. Ng S, Kessler L, Srivastava R, Dusek J, Duncan D, et al. (2010) Growing practice specialists in mental health: addressing stigma and recruitment with a nursing residency program. Nursing Leadership (Toronto, Ont) 23: 101-112.

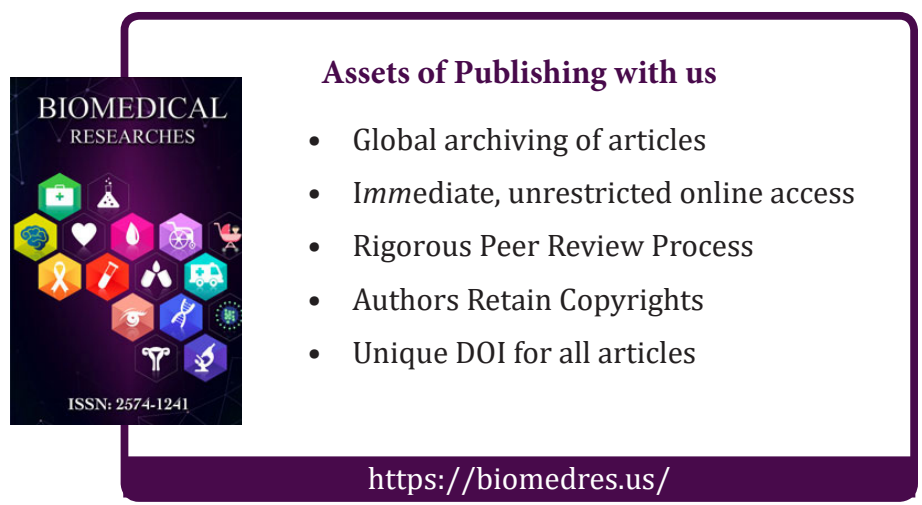

